\title{
Free-floating Left Atrial Ball Thrombus in Non-valvular Atrial Fibrillation
}

\author{
Nozomi Watanabe, MD*, Takashi Akasaka, MD*, Noriko Okahashi, MD*, \\ Nozomi Wada, MD*, Takahiro Kawamoto, MD*, Kazuo Tanemoto, MD** \\ and Kiyoshi Yoshida, MD* \\ *Department of Cardiology \\ **Department of Thoracic and Cardiovascular Surgery, Kawasaki Medical School, Kurashiki, \\ Japan
}

\begin{abstract}
Summary
A giant ball-thrombus was found in the left atrium in 78 year-old female with non-valvular lone atrial fibrillation. Intraoperative echocardiography revealed the thrombus was floating freely inside the left atrium. The thrombus was sometimes scarcely entrapped into the mitral annulus and bounded back toward the left atrium. The removed thrombus was $45 \times 35 \times 20 \mathrm{~mm}$ in size.

(J Echocardiogr 2005; 3: 91-92)
\end{abstract}

Key words: ball thrombus, non-valvular AF

A 78-year-old female with non-valvular lone atrial fibrillation underwent transthoracic echocardiography as a routine practice. She had been administered anticoagulation therapy, which was not well controlled, and had had a history of syncope several months before the exam. A giant mass was found in the left atrium by transthoracic echocardiography, and transesophageal echocardiography showed a large, mobile ball throm-
A

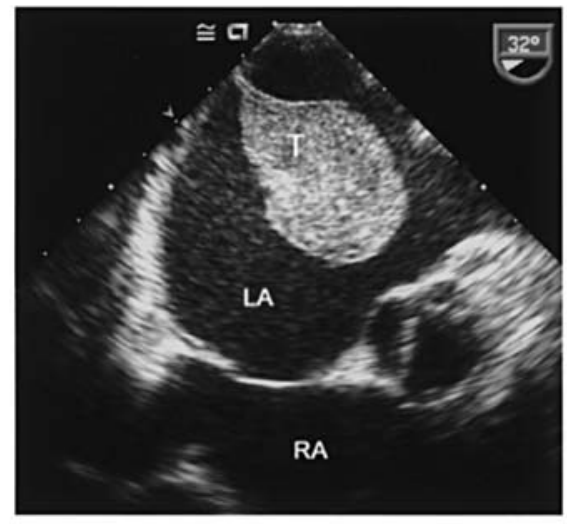

Received April 30, 2005; revision received June 1, 2005; accepted June 10, 2005

Address for correspondence: Nozomi Watanabe, MD Department of Cardiology, Kawasaki Medical School, 577 Matsushima, Kurashiki 701-0192, Japan.

Telephone: +81-86-462-1111

Fax: +81-86-462-1199

E-mail: non@med.kawasaki-m.ac.jp

(C) 2005 Japanese Society of Echocardiography

B

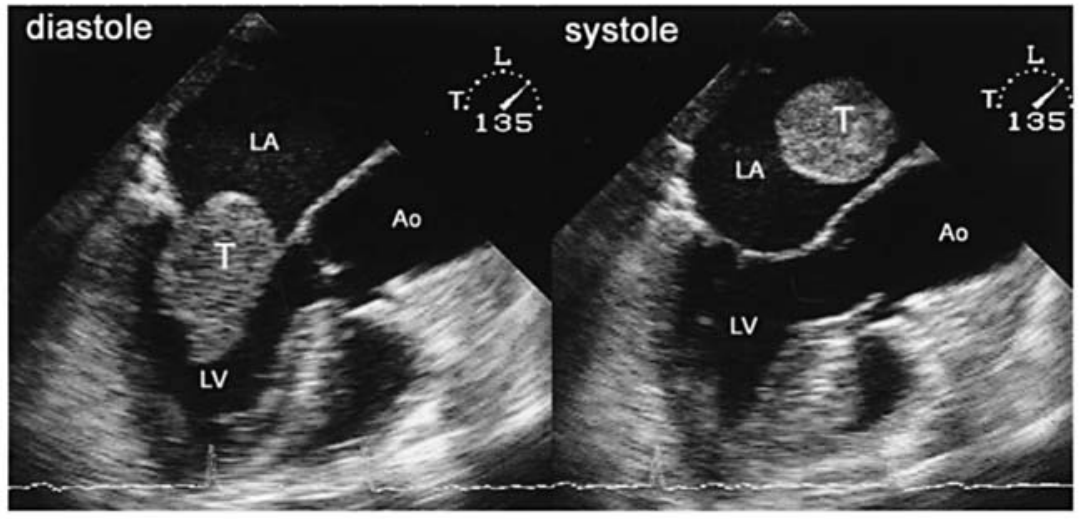

Fig. 1. Preoperative (A) and Intraoperative (B) transesophageal echocardiogram

A: A large, mobile ball thrombus was found by transthoracic echocardiography. The thrombus was attached to the left atrial wall with thin stalk.

B: The thrombus was floating freely inside the left atrium. It was sometimes scarcely entrapped into the mitral annulus in diastole and bounded back toward the left atrium in systole.

(T: thrombus, LA: left atrium, RA: right atrium, LV: left ventricle, Ao: ascending aorta) 


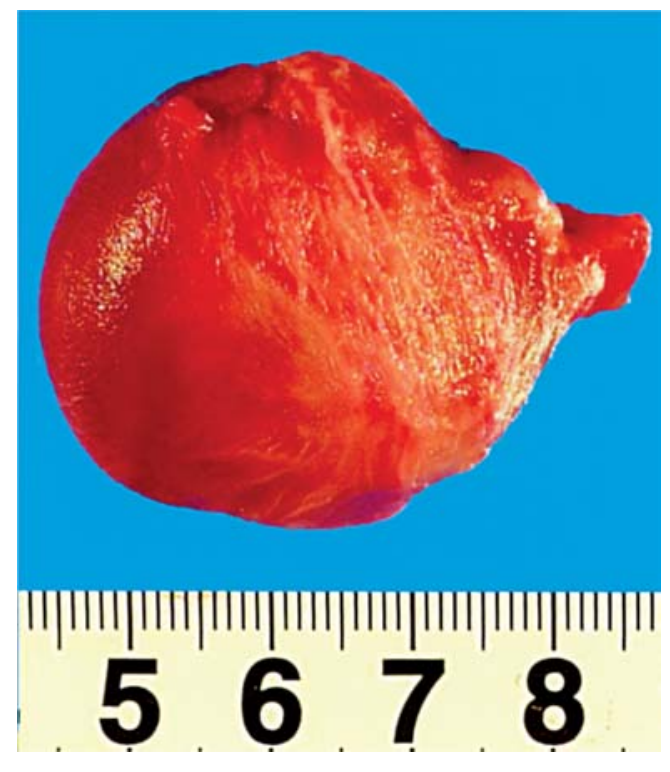

Fig. 2. Surgically removed thrombus A soft, ball-shaped thrombus (45x $35 \times 20 \mathrm{~mm}$ in size) was surgically removed. bus attached to the left atrial wall with thin stalk (Figure 1A). There was no finding of mitral stenosis in this patient. Surgical removal was planned immediately. Intraoperative echocardiography revealed that the thrombus did not attached to the left atrial wall anymore and was floating freely inside the left atrium. The thrombus was sometimes scarcely entrapped in the mitral annulus and bounded back toward the left atrium (Figure 1B). The removed thrombus was $45 \times$ $35 \times 20 \mathrm{~mm}$ in size (Figure 2 ). In this case, fortunately, the ball thrombus was large enough to be trapped in the mitral annulus when it finally broke away from the left atrial wall between the times from transesophageal echocardiography to the surgery. This lady escaped from sudden death or critical stroke. 